\title{
Enriching the Toxicology Experience through Twitter
}

\author{
Peter R. Chai ${ }^{1}$
}

Published online: 22 October 2015

(C) American College of Medical Toxicology 2015

Nearly a year ago, the University of Massachussetts' Division of Medical Toxicology entered the world of Twitter in order to participate in an increasingly online virtual classroom. Each day, we tweet our way through weekly toxicology conferences, national journal clubs sponsored by the American College of Medical Toxicology (ACMT), and toxicology-related events in the media. Tweets help us gather the most pertinent information we are learning. We group them by relevant topics through hashtags and save ideas for review at a later date. It is without question that Twitter has become important in medicine as a tool to educate trainees, respond to current events, and inspire each other [1]. Additionally, partnerships between academic blogs and major scientific journals show the relevance and importance of social media, like Twitter, as a teaching tool in the new digital age of medical education [2].

Twitter is an online, microblogging platform that allows creation of unique user identifiers (Twitter handles) through which short, 140-character messages can be composed (Tweets). Tweets are disseminated through a user's followers and can be marked as a favorite message or broadcasted to another group of followers (retweet). The addition of a hashtag (\#) within the message permits aggregation of historical tweets (mining). Twitter is one of several social media platforms in existence.

Peter R. Chai

peter.chai@umassmemorial.org

1 Division of Medical Toxicology, Department of Emergency Medicine, University of Massachusetts Medical School, 55 Lake Ave North, Worcester, MA 01655, USA
A recent editorial in this journal predicted the future of Twitter in our field as an engine of education and improved patient care [3]. Medical toxicology has always been at the forefront of technology, utilizing novel filing systems and telephones to establish a network of poison centers across the USA and pioneering an expansion into telemedicine to reach institutions without poison expertise [4, 5]. Twitter can enrich toxicology by enhancing education and broadening exposure to conference content. At the same time, toxicologists need to be cognizant of patient privacy concerns and how Twitter is redefining the idea of academic impact.

\section{Twitter and Toxicology Education}

Within medical toxicology, popular blogs and Twitter users have aggregated information into the Free Open Access Meducation Toxicology (\#FOAMTox) movement that readily gives students access to experts in toxicology $[6,7]$. Tweets containing links to useful websites and podcasts supplement traditional toxicology education. Hashtagged tweets through \#FOAMTox create the opportunity for learners to reach out to experts in real time, crowd sourcing their education and filtering toxicology information through leaders in our specialty. Participation in a vibrant online community of students, bloggers, physicians, toxicologists, journalists, and organizations is now commonplace among our peers.

As I tweet during our division's toxicology conference at the University of Massachusetts, I am greeted by favorites and retweets from toxicologists throughout the world. We pose a question regarding the management of snake bites and turn to our experts at another toxicology fellowship. Soon, Twitter explodes with comments, links to literature, and up-to-date clinical practice guidelines from experts in envenomation. A rare poisoning in our fellowship is commonplace in another 
part of the country, and we are privy to the clinical experience of regional experts at a moment's notice through Twitter. These discussions contribute to our academic growth and grow the toxicologist presence on social media.

Generating an online discussion is also useful and effective to disseminate information learned through national and regional conferences to our colleagues [1, 8]. Real-time tweets during academic conferences are an effective method to spread and catalog information for those at the conference and those who follow conference hashtags through Twitter [8]. Social media aggregators, such as Symplur can be used to gather valuable hashtag-oriented metrics that reflect the reach and influence of academic conferences. In the past year, 123 toxicologists on Twitter at the ACMT Annual Scientific Meeting generated over 500,000 impressions (views from unique users on Twitter) through 911 tweets [9]. Improving conference penetrance gives our specialty exposure in key media outlets allowing us to provide valuable insight in conversations with the public and other professionals.

\section{The Twitter Case Report}

Toxicologists continue to use the case report as a method for disseminating management strategies in esoteric exposures [10]. When adapted to social media, the Twitter case report becomes a teaching tool, an instrument of public health outreach, and another method for us to connect to patients. Our weekly conference at the University of Massachusetts begins with tweets about an interesting case - just enough to generate a broad differential diagnosis from our live audience and our Twitter audience [11]. Subsequent case history streams in tweets and draws participants and learners to our conference. Questions posed through Twitter can be answered through tweets by remote toxicologists and discussed during conference. Pertinent journal articles explaining viewpoints of toxicologists participating in an online Twitter conference are shared, favorite, retweeted, and archived for reading. Mining tweet history allows retrospective review in a free and public forum to study pertinent toxicology content.

\section{Patient Privacy}

Social media is a powerful tool for medical education, but unstructured use can be a venue for ethical and legal violations to occur. Compliance with the Health Information Portability and Privacy Act (HIPAA) must remain paramount, and Twitter use in any medical field should include a commitment to protect the identities of patients [12]. Our obligation to patient privacy must remain in our minds as we tweet, blog, and podcast toxicology education. We must be conscious that subtle case information like the location of poisoning or patient gender and age can be used to determine the identity of the patient with a unique exposure. Withholding age, sex, location, and other demographic information can protect patients while providing enough case details in engaging an educational lesson through Twitter [13].

\section{The Twitter Effect on Academics}

Intercalating our literature and opinions as toxicologists through social media can improve popular exposure to our specialty, broaden our outreach, and provide us with opportunities to discuss pertinent topics. Article sharing on Twitter also drives increased views and exposure to literature [14]. In addition to serving as a repository for specific literature for a toxicology fellowship, tweets can be used to drive viewership towards important articles in our specialty while improving article metrics. Novel metrics, like altmetrics, are frequently used as an alternative measure of academic impact. Altmetrics integrate traditional exposure to literature through medical library subscriptions with tweets on journals and article downloads to provide an alternate assessment of article impact [15].

For toxicologists with academic careers, viewership and social media shares of manuscripts will invariably become important aspects of education, outreach, and possibly promotion. Instead of continuing to use traditional methods for ranking and promotion by accounting for publications and citations, academic institutions may consider altmetrics. This could include curation of an influential social media profile and other novel determinants which regard the impact of published papers such as the H-index or Eigenfactor score [16]. Going forward, integrating the social media exposure of published literature must be interpreted in conjunction with traditional measures of academic productivity.

\section{Where do We Go from Here?}

Twitter was recently called a "vast, underutilized tool that has the potential to transform, expand, and improve our field" [3]. One hundred forty characters may seem short, but the message contained can expand exponentially, exposing readers to our great specialty. A careful and directed social media strategy can help us flourish, educate, and promote ourselves through Twitter. So go on, if you have yet to create a Twitter account, do it - join the growing community of toxicologists on Twitter. For those with Twitter accounts, follow us, tweet responsibly, and favorite, retweet, and hashtag your way to an enriched toxicology experience. 
Acknowledgments Special thanks to Dr. Trevonne Thompson (@trevthomps) and Dr. Christine Murphy (@cmurphytoxdoc) for their assistance in writing this editorial.

\section{Compliance with Ethical Standards}

Funding Sources The author is supported by the Joseph P. Healey Endowment

Conflict of Interest I have no conflicts of interest to report.

\section{References}

1. Choo EK, Ranney ML, Chan TM, Trueger NS, Walsh AE, Tegtmeyer $\mathrm{K}$ et al. Twitter as a tool for communication and knowledge exchange in academic medicine: a guide for skeptics and novices. Med Teach. 2014:1-6. doi:10.3109/0142159x.2014. 993371.

2. Faust J. Rise of the Free Open Access Medical Education Online Journal Club. ACEP Now. 2015.

3. Cheema N. Tweet this \#toxicology2.0. J Med Toxicol. 2014;10(1): 7-9. doi:10.1007/s13181-013-0371-2.

4. Skolnik A. Telemedicine and toxicology: back to the future? J Med Toxicol. 2013;9(3):217-9. doi:10.1007/s13181-013-0313-z.

5. Chai PR, Wu RY, Ranney ML, Porter PS, Babu KM, Boyer EW. The virtual toxicology service: wearable head-mounted devices for medical toxicology. J Med Toxicol. 2014. doi:10.1007/s13181014-0420-5.

6. Gussow L. Toxicology rounds: the future of medical toxicology? Twitter of course. Emerg Med News. 2014;36(10):12.
7. Rotella JA, Wong A, Greene S. @ Toxicology in the Twittersphere: more than just 140 characters. Emerg Med Aust. 2013;25(6):620. doi:10.1111/1742-6723.12146.

8. Djuricich AM, Zee-Cheng JE. Live tweeting in medicine: 'Tweeting the meeting'. Int Rev Psychiatry (Abingdon, England). 2015:1-7. doi:10.3109/09540261.2014.1000270.

9. Symplur Healthcare Hashtags. \#ACMT2015 Analytics. 2015. http://www.symplur.com/healthcare-hashtags/acmt2015/ analytics/?hashtag=acmt $2015 \&$ fdate $=03 \% 2 \mathrm{~F} 26 \% 2 \mathrm{~F} 2015 \&$ shour $=$ $00 \& \operatorname{smin}=00 \&$ tdate $=03 \% 2 \mathrm{~F} 29 \% 2 \mathrm{~F} 2015 \&$ thour $=00 \& \operatorname{tmin}=00$.

10. Ruha AM. The case report: a tool for the toxicologist. J Med Toxicol. 2009;5(1):1-2.

11. University of Massachusetts Division of Medical Toxicology. @Umasstox. 2015. https://twitter.com/UMassTox.

12. Shore R, Halsey J, Shah K, Crigger BJ, Douglas SP. Report of the AMA Council on Ethical and Judicial Affairs: professionalism in the use of social media. J Clin Ethics. 2011;22(2):165-72.

13. Farnan JM, Snyder Sulmasy L, Worster BK, Chaudhry HJ, Rhyne JA, Arora VM. Online medical professionalism: patient and public relationships: policy statement from the American College of Physicians and the Federation of State Medical Boards. Ann Intern Med. 2013;158(8):620-7. doi:10.7326/0003-4819-158-8201304160-00100.

14. Allen HG, Stanton TR, Di Pietro F, Moseley GL. Social media release increases dissemination of original articles in the clinical pain sciences. PLoS One. 2013;8(7), e68914. doi:10.1371/journal. pone. 0068914.

15. Trueger NS, Thoma B, Hsu CH, Sullivan D, Peters L, Lin M. The Altmetric score: a new measure for article-level dissemination and impact. Ann Emerg Med. 2015. doi:10.1016/j.annemergmed.2015. 04.022.

16. Hirsch JE. An index to quantify an individual's scientific research output. Proc Natl Acad Sci U S A. 2005;102(46):16569-72. doi:10. 1073/pnas.0507655102. 